\title{
A Case-Study in Cross- Disciplinary Student Work: a CNC-Manufactured Body for FSAE Racing
}

\section{INTRODUCTION}

The project discussed here involves the contribution of architecture students towards the design and fabrication of the body for an openwheel race-car for the annual SAE competition (Society of Automotive Engineers). The development of this body constitutes only a portion of a wider project that involves engineering a fully functional car within the time-span of one academic year, within the school of Mechanical Engineering. Naturally, the overall project involves a wide range of skills that exceed architectural training and the author is interested in this collaborative effort between two distinct departments and the logistics involved in its materialization.

Although the work is important in terms of "process" - looking at how different disciplines may work together - the author will focus on the pedagogical issues that have influenced the design, and conversely, examine how the project itself can promote new modes of instruction within academic curricula.

How can reviewing this collaboration from a pedagogical perspective help enhance the team's performance?
The project could be conceptually broken down to Engineering and Architectural input. The SAE team was separated into the following subteams, which focused on certain parts of the car: Chassis, Suspension, Drive-train, Engine, Electronics, Body \& Aerodynamics, Manufacturing, Business, Ergonomics \& Driver training. This discussion will focus around the Body and Aerodynamics team, as this was the one receiving feedback from the architecture students. The design process for the body was considered initially at small scale $(25 \%, 75 \%)$ before moving on to the full-scale components. A series of digital versions were produced, physical prototypes were fabricated, tested, then

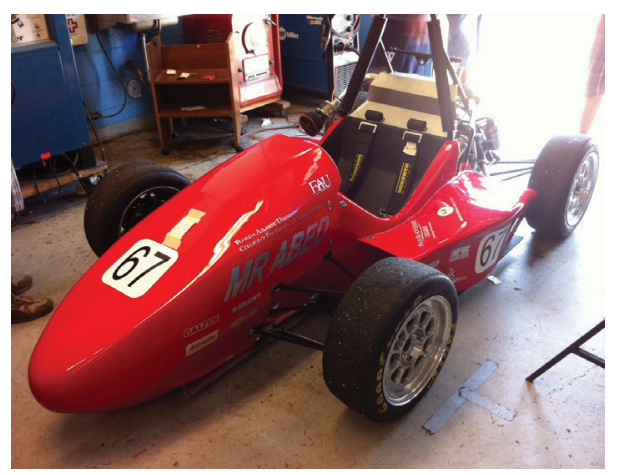

Figure 1: Owls Racing 2011 car in the FAU machine shop. (all images courtesy of author) 
revised before a final version was selected and manufactured at 1:1 scale (Fig.1).

Why is this collaboration worthwhile for: a. architects $b$. engineers??

This is an opportunity for architects to evaluate their in-house methods by learning through collaboration to inform other architectural design projects, as well as improve interaction with other specialists towards further joint works in the future.

\section{DISCUSSION: PROCESS}

\section{Significance of Time in designing}

An explanation of the project's process over time is necessary to understand the constraints the team had to work with (time-chart run from September to April). The steps needed to optimize the work-flow among students have to be analyzed as well as a possible efficient mode of working-communication between Architecture and Engineering students.

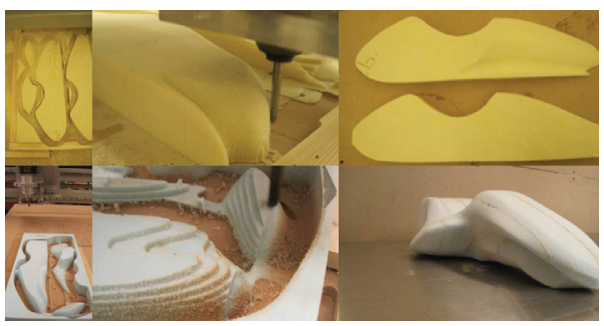

Figure 2: CNC-Prototyping of Options A, B (scale 25\%)

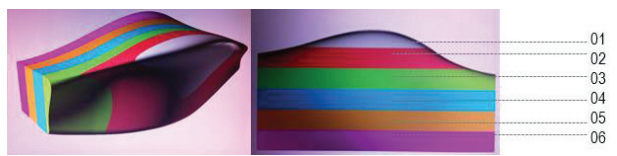

Figure 3: Side-pod digital model is contoured into 6 parts to facilitate full-scale fabrication

During the 2011 year, prototyping on the body was carried out without any prior data acquisition from analysis. Furthermore, the simulation of the physical prototypes (Fig.4) occurred too late to take the feedback into account. Most importantly, the time constraints forced the team to produce the plugs for the body parts manually, not being able to take advantage of the CNC facilities for the full scale parts (see Table 1.1).

For the 2012 car a tighter schedule is proposed, where simulations are carried on both the digital and physical models (before and after the winter break respectively). In addition to this, a closer working pattern between the Body team and Owls Racing can ensure a sufficient time margin to CNC-machine the plugs for the final body parts, sometime around spring break (Table 1.2).

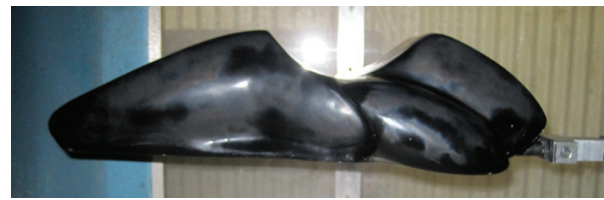

Figure 4: Final scaled prototype in windtunnel.

It has to be noted that the 2011 car was a 1 - year car (unlike previous iterations which spanned over two academic years) and so the time constraints were much harder - this also had an impact on the time available for the architects' team to design considering that the chassis had to be finalized before the final body shape was decided! This indicates that close collaboration needs to occur between the teams:

Constraint: The interaction between Architecture and Engineering students needs to occur as smoothly as possible to stay within the desired time-frame. Architecture students need to be considered as part of the Body/Aerodynamics team and not as a separate entity (Fig.5).

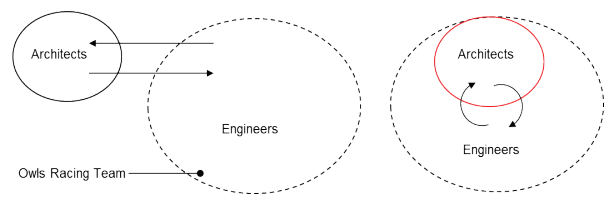

Figure 5: Schematic mode of interaction between two disciplines (typical - suggested). 


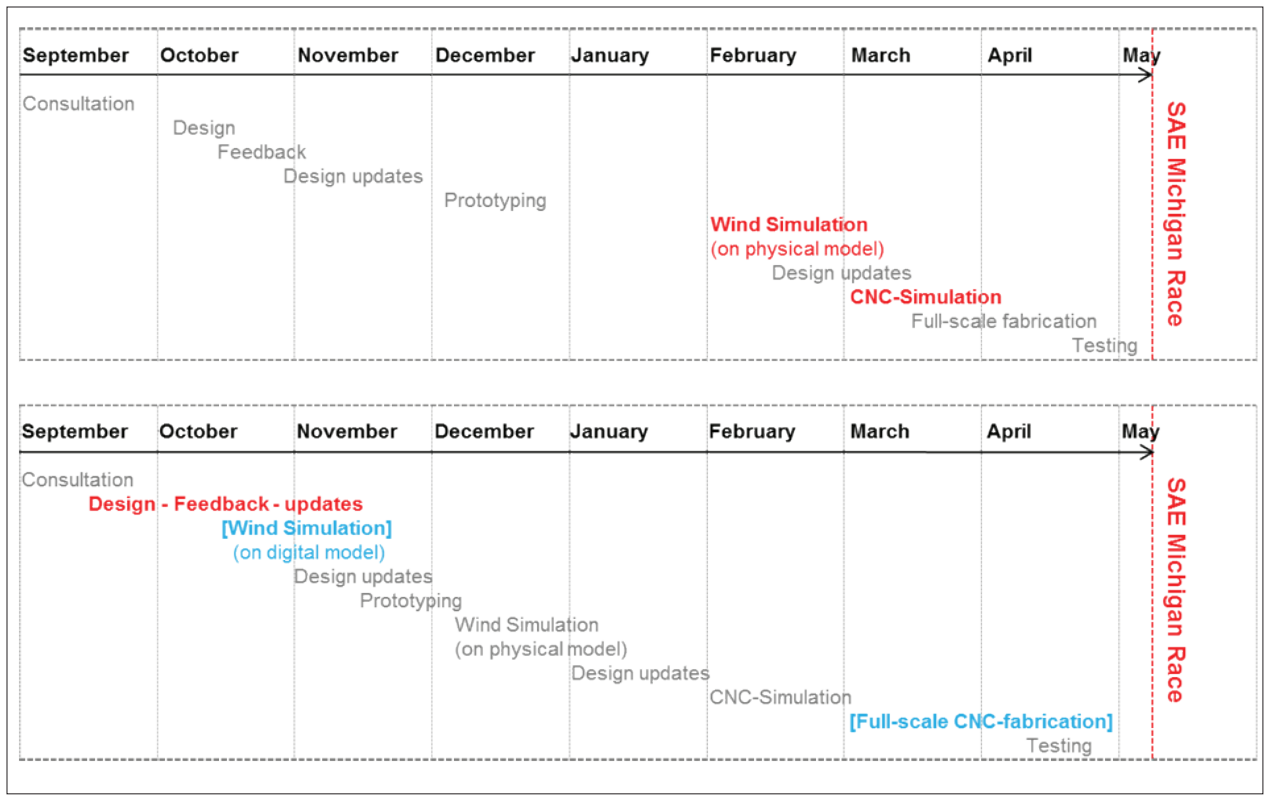

Tables 1.1 and 1.2: Project time-line for the design and manufacturing of the Body parts (existing \& proposed) Stages in bold indicate areas which need revising, the ones in blue indicate stages that were not present in the 2011 car design.

\begin{tabular}{|c|c|c|c|c|c|c|c|c|}
\hline & School (Position*) & U of Michigan (6) & UAS Zwickau (7) & UAS Graz (10) & Karlsruhe I.T.(41) & U of Kansas (9) & Oregon State (1) & FAU (45) \\
\hline SAE Event & Working Model & & & & & & & \\
\hline \multirow[t]{3}{*}{ Michigan '11 } & $\begin{array}{l}\text { Collaboration } \\
\text { w. Architect }\end{array}$ & NO & NO & NO & NO & NO & NO & YES \\
\hline & $\begin{array}{l}\text { Collaboration } \\
\text { w. Sponsor }\end{array}$ & YES & $?$ & YES & NO & NO & ? & NO \\
\hline & $\begin{array}{l}\text { Collaboration } \\
\text { w. other University }\end{array}$ & NO & NO & NO & NO & NO & YES (Ravensburg) & NO \\
\hline California'11 & Collaboration??? & & \multicolumn{4}{|c|}{ [Data from the California event is required to compare the events] } & & \\
\hline
\end{tabular}

Table 2: Chart showing collaborative schemata within SAE teams participating in the Michigan 2011 SAE Race. FAU (Owls Racing)shown in light blue.

Proposal: Introducing a specialist analysis software elective (ie. Solidworks) which can be taken by the students from the school of Architecture to provide non-engineering students with some experience in kinematics, analysis and even feature modeling. This can also help establish relations between different colleges (ie. Architecture - Engineering).

\section{Versioning - Feedback loops}

It is important to reflect on the nature of production and evaluation during the project: the 'versioning' which was implemented in the working process of the students is analogous to the evolutionary mode of producing 'mutations' through parametric process, albeit this being an analog process! It may be preferable and more efficient to include the input from 
engineering students early in the process so that all initial versions reflect the real constraints of the project and are not considered as separate 'architectural solutions' which then need to be corrected through additional technical input (see proposed time-chart: Table 1).

\section{Similar Precedents within SAE racing}

Is it possible to locate other joint ventures within SAE? The mode of fabrication management for other SAE teams has to be analyzed, looking at strong teams from the Michigan and California racing events to demonstrate the decisions relative to manufacturing based on the resources available within each team: this year, we found out that some teams (University of Michigan, Ann Arbor) exclusively out-sourced the fabrication of body parts (ie. female plugs) to their sponsors while others (University of Applied Sciences, Graz) used specialized facilities provided by their sponsors to complete their body manufacturing themselves. It may be interesting to identify any similar collaboration between Engineering and Architecture schools elsewhere, and how common these may be. The author discovered that almost all teams worked exclusively within their department (see Table 2), even in the case of Universities which possess significant CNC resources in their respective Architecture Schools (ie. University of Michigan, Ann Arbor). Why are such collaborations not so frequent? One has to examine the potential flaws of cross-disciplinary work.

Even though collaboration between Architects and Engineers seems rather uncommon, other type of joint schemata emerged from the 2011 race (Table 2): collaboration between School - Sponsors, or inter-university ones between School - School (Oregon State University \& Duale Hochschule Baden-WürttembergRavensburg formed 'Global Racing'). It is interesting therefore, to reflect on how synergetic relationships may be either academically or commercially oriented.

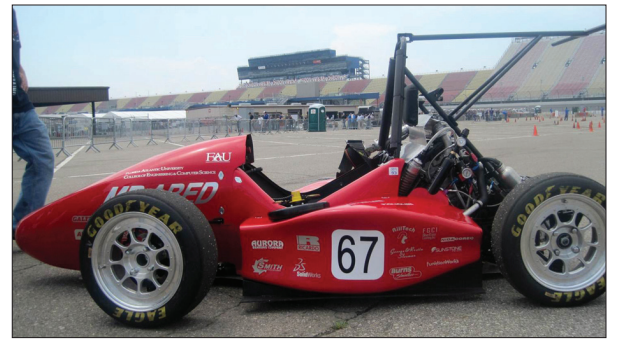

Figure 6: Owls Racing 2011 car at the Michigan International Speedway. (all images courtesy of author)

\section{Architecture vs. Engineering}

Traditionally, a rift has existed between the two disciplines, which dates back to the time when Architecture was regarded as a specialized field; this eventually resulted in the conceptual separation from the construction aspect thereby establishing Engineering and contracting sub-disciplines1. Today, Architecture and Engineering remain complementary, but Engineering has been further classified into more sub-disciplines, from which Architecture mostly relates to structural engineering. It is the intent and hope of such collaborations to initiate a dialogue between Architects and other types of Engineers within academia, to find common ground and learn from each other. The 'digital' tendencies which characterize contemporary Architectural design are pointing towards other fields so that architects can expand their skills and increase the technological sophistication of their constructions. An 'Integrative' approach one which encourages cross-disciplinary work has been much favored in recent years and we believe this may be the way towards future problem-solving in more than one disciplines. For this to happen, nevertheless, it is important that ways and processes are adopted which can alleviate the qualitative differences existing between the two fields, so that cross-fertilization may occur more seamlessly, and more Engineering schools may turn to their Architecture counterparts for help in component designing. 
An elective course open to both Architecture and Engineering students may be offered; this, however, may not work everywhere, but is contingent upon certain factors:

a. School size: enough students are necessary, who can take CNC-fabrication classes so that such projects can be implemented. As this is a fairly advanced project for beginners, perhaps it is best suited for students with some prior experience in digital design and manufacturing, which points to the creation of more than one fabrication courses 2 . A need is becoming clear, to consider such courses not as electives but rather as a 'core' components.

b. School curriculum and its flexibility: This needs to be considered both within the school of Architecture and Engineering.

- Architecture: The faculty responsible may introduce pedagogical 'sequences' of courses which gradually build up an expertise for each of the students. Students would, then, be free to evaluate those sequences and adopt some within their courses. If the current system only allows a very small number of electives from Architecture, then students are never able to 'orchestrate' the continuity and cross-pollination of their courses by taking more than one in any subject (ie. basics, and advanced fabrication). This is a critical element that should not be overlooked as such opportunities to define specific areas of focus will enhance the students' marketing potential in terms of securing employment later on. Can this model only operate within a Graduate curriculum?

- Engineering: In the current team described herewith, the positions of team leaders required previous similar experience. The majority of the students who were in charge of the sub-groups were pursuing graduate degrees, therefore possessing organizational and management skills required for the coordination of the design and manufacturing work. The teams also recruited less experienced undergraduate students, with the intention of (those students) participating in more than one SAE cars consecutively, thus building experience in this type of project over time, to the point where they can progressively become team leaders themselves.

The complexity of managing such a project naturally presupposes advising from senior faculty members. This has been available albeit in an unofficial way, as the project is not part of the Engineering curriculum. By now it is clear that a framework needs to be set up, which conceives this work as a formal effort within the school; this recognition can offset several issues which the current team has had to face, such as comfortably securing substantial sponsorship from significant clients, organizing and adhering to a strict time-line that is constantly supervised by several specialist faculty advisers and finally receiving informed feedback BEFORE the race. Comparing this current model with those existing in other SAE teams around the country, indicates that those teams with the strongest sponsors (Fig. 7) usually perform well and are perceived as distinct well-known entities with-

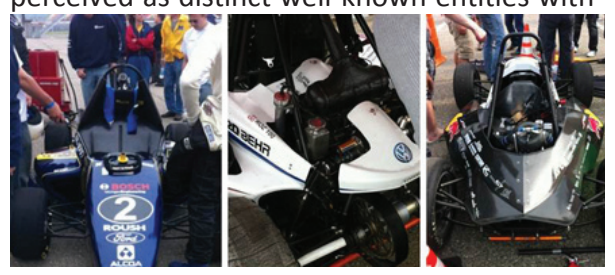

Figure 7: SAE team sponsors: Bosch, VW, Red Bull (University of Michigan, UAS Zwickau, UAS Graz).

in their academic context.

It may, therefore, be worth for Owls Racing, to look at such examples in order to find ways of incorporating SAE racing within Mechanical Engineering curricula, and establish an analogous structure. This integration may be materialized in the form of distinct elective courses, special "funded" research initiatives, thesis projects or even internship-related work. To capitalize on these possibilities, and considering that several students graduate from FAU with the intention 
to pursue Master degrees in Motorsport Engineering, the College of Engineering might consider the acquisition of faculty with appropriate expertise in Automotive Engineering. Overall, it seems there is substantial gain from adoption of SAE racing in the curriculum, as the project itself may become a powerful marketing tool to attract students into the school (as the author has discovered by the testimonies of the students themselves).

\section{CONCLUSION}

In retrospect, this has been a challenging but also rewarding project, thanks to the enthusiasm of both the SAE team and my students, who engaged the task despite the unprecedented type of work involved. Unlike Architectural projects, such work involves precision making and tolerances which are very different to the ones typically used in Architecture. Nevertheless, the students embraced this effort, primarily because it is a "live" project with both digital and physical manifestations at a high level. From our observation of the most successful teams, we identified a number of factors that would give an edge to racing teams: these were the application of "unique features"; securing strong industrial Sponsors; and forming "joint racing teams" (see Table 2).

Based on these observations, and assuming the collaboration between the two schools will continue (based on mutual intentions to work with each other thanks to this year's successful outcome3), the team is considering three key-points that need to be addressed in the evolutionary stage of this project, to achieve an improved version of the car:

a. Design decisions ${ }^{4}$ (and the format of making those decisions)

b. Time Management (workflow)

c. Sponsorship (this relates to the above especially to the Design decisions and vice-versa)

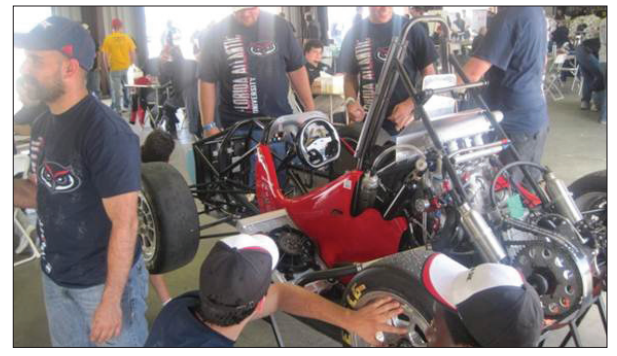

Figure 8: Owls Racing team 2011 Design presentation to the SAE judges.

\section{Integrative Model}

Based on other recent projects, I am increasingly convinced that a strong common thread exists among the way that all types of designers are thinking today, even if the immediate context of their work differs in type or scale. More and more scientists have begun to capitalize on their expertise Passively - that is, not by merely exercising their traditional skills through research but through consulting other disciplines, and vice versa. As educators, collaborations of this kind are remarkable because of what instructors and students stand to gain academically!

In retrospect, the title of this presentation contains a slight touch of irony considering the project was eventually not produced with CNC-machining (apart from the scaled prototypes). Although all necessary simulations were executed to calculate fabrication times estimated to approximately one and a half day for each side-pod (that was deemed to be the most complex part), lack of time dictated that a manual production might be preferable. ${ }^{5}$

As far as the author is concerned, the title remains important in so far as it underlines and re-iterates the need to not only collaborate, but collaborate efficiently! The conditions of this collaboration need to be optimized, so that this stays both productive and instructive towards students and faculty alike. 
As a result, it is clear that this is an opportunity to reexamine the mode of collaboration among different disciplines, and academic departments, finding ways to make this seamless. During a time where Technology underpins an ever larger portion of the decisions made within this industry, architects and engineers need to learn how to speak the language of each other so that engineers can relate to architects - and vice versa. This may involve, for example becoming familiar with tools for analysis which are used in the engineering domain, as we already discussed. To familiarize themselves with such instruments, perhaps architects ought to engage into dialogue which removes them from their comfort zone, by attending non-architectural conferences. Only then, can the feedback received be architecturally 'unfiltered'.

\section{ACKNOWLEDGMENTS}

I would like to thank the following Architecture students: Monica Arcila, Jammy Chong, Mauricio Feldsberg, Juan Mora, Xavier Salas, Jose Torres. Special thanks to all members of the Owls Racing team for taking me along on this journey, and Dr. Oren Masory from the Department of Mechanical Engineering for inviting us to participate in this project.

\section{ENDNOTES}

1 These, over time, came to be regarded as essential elements which complement - and rationalize - Architects' design decisions. It is interesting to situate this historically in the Enlightenment, although this began much earlier when Architecture was separated into theoretical and practical constituents by Alberti during the Renaissance.

2. To establish such course sequences a school may require a fairly large student body.

3. Owls Racing placed $45^{\text {th }} / 122$ overall, and secured $15^{\text {th }}$ place in Design \& Manufacturing, receiving very favorable comments from the SAE judges (Fig.8).

4. For example, the choice to employ CFD analysis for the design of the Body, the decision to make female over male plugs to ensure better finish, and the introduction of unique features like CarbonFiber parts can give an edge to the team, as we have observed from this year's race.

5. Manufacturing the plugs manually did not ensure better finish, and may even perhaps have taken the same time as CNC-machining, however it was a method followed in previous years and therefore any possible problems were more foreseeable. 